\title{
The Biosynthesis of Monoterpenoid Indole Alkaloids from Strictosidine ${ }^{1}$
}

\author{
By Naotaka Nagakura, (Mrs.) Martina Rüffer, and Meinhart H. Zenk, "Lehrstuhl für Pflanzenphysiologie, \\ Ruhr-Universität Bochum, D 4630 Bochum, W. Germany
}

\begin{abstract}
The differential incorporation of doubly labelled strictosidine and vincoside into several indole alkaloids belonging to the Corynanthe ( $3 \alpha$ and $3 \beta$ series), Aspidosperma, and /boga types in three plant families has been studied, and it has been demonstrated that only strictosidine is incorporated while vincoside is metabolically inert in these plants with regard to alkaloid formation. During the conversion of strictosidine into the $3 \beta$-indole alkaloids, the hydrogen atom at the 3-position is lost, while it is retained during the biosynthesis of the $3 x$ alkaloids. The chemical synthesis of $\left[7-{ }^{3} \mathrm{H}\right]$ secologanin, an important intermediate for further work in the biosynthesis of monoterpenoid alkaloids, is also described.
\end{abstract}

THE fundamental research of Battersby and Arigoni and their associates ${ }^{2}$ during the past decade has established the central role of loganin and secologanin (2) in the biosynthesis of a multitude of monoterpenoid indole alkaloids. Secologanin (2) is the ultimate precursor for the $\mathrm{C}-9 / \mathrm{C}-10$ non-tryptamine carbon skeleton common to the majority of indole alkaloids. Tryptamine (1) and secologanin (2) condense to form an intermediate<smiles>NCCc1c[nH]c2ccccc12</smiles>

(1)<smiles></smiles>

(3)

which was shown to be biologically rearranged to the diverse structures of the indole alkaloids found in nature. $^{2}$ Chemical condensation of (1) and (2) yields a mixture of the two epimers strictosidine (3) and vincoside (4), of which vincoside was shown to be the sole precursor for the biosynthesis of the indole alkaloids. ${ }^{3}$ On the other hand, prior to this investigation ${ }^{3}$ the other epimer had been isolated from Rhazia stricta in high yield, named strictosidine (3), and assumed to occupy a crucial position in the postulated biosynthesis of these alkaloids. ${ }^{4}$ The correct stereochemical relationship of the precursor to the products has since then been a matter of controversy and confusion. ${ }^{5}$ The absolute stereochemistry of (4) was established unequivocally ${ }^{6,7}$ to be $(R)-3 \beta$. This has recently been confirmed by $X$-ray diffraction. ${ }^{8}$ Based on this unequivocally established configuration of (4) we were able to prove that, in contrast to previous assumptions, ${ }^{5}$ strictosidine (3), with
$(S)-3 \alpha$ stereochemistry, is indeed the key intermediate in the formation of the three classes of monoterpenoid indole alkaloids (Aspidosperma, Iboga, and Corynanthe) in Catharanthus roseus (syn. Vinca rosea) plants as well as a variety of other species in cell cultures by in vivo and in vitro techniques.9,10 The crucial enzyme catalysing the condensation of (1) with (2) to yield exclusively the $\alpha$-epimer strictosidine (3) has been discovered and

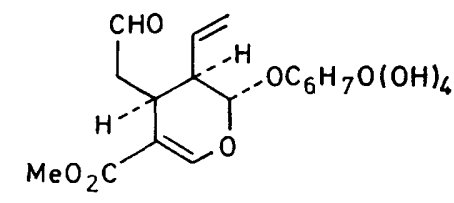

(2)

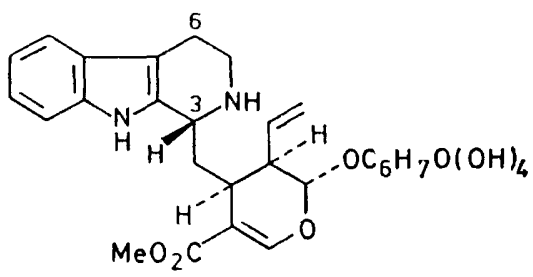

(4)

named strictosidine synthase. ${ }^{10}$ The role of $(3)$ as a precursor in vivo has been independently confirmed using Rhazia species ${ }^{11}$ and $C$. roseus. ${ }^{12}$ The above observations were later confirmed ${ }^{13}$ also by in vitro experiments using $C$. roseus callus tissue. All these results are in accord with reports on the biosynthesis of camptothecin, an alkaloid of taxonomically distant origin, for which strictosidine lactam was previously ${ }^{\mathbf{1 4}}$ found to be a precursor and recently ${ }^{15}$ also (3). It can therefore be taken for granted, that the $\alpha$-epimer (3) is the biological precursor for the majority of indole alkaloids, especially those with the $3 \alpha$-configuration. However, the question remains whether (3) is the universal precursor for all those indole alkaloids which are derived from the condensation of (I) and (2). This latter point is especially important for an alkaloid family with $\mathrm{C}-3 \beta$ stereochemistry. Since it has been postulated, based on biomimetic experiments ${ }^{16}$ which were assumed to 
duplicate the in vivo process, that (3) is the precursor for $3 \alpha$ - and (4) for $3 \beta$-alkaloids, it has been proposed that vincoside (4) would have a role as an in vivo precursor for alkaloids with the $\mathrm{C}-3 \beta$ configuration in those plants where these products occur. ${ }^{12}$ To test this latter possibility and to gain clarity as to the assumed universal role of (3) as precursor for monoterpenoid indole alkaloids, $\left[{ }^{14} \mathrm{C}\right]$-labelled (3) and $(4)$ were fed to a range of plants and their respective incorporation determined. To trace also the fate of $3-\mathrm{H}$ of (3) and (4), a tritium label was introduced into this position. This was achieved by synthesizing $\left[{ }^{3}{ }^{3} \mathrm{H}\right]$ secologanin (2), a substance which is also important for future work on the<smiles>C=CC1C(OC=O)OC=C(C(=O)O[Na])C1CC=O</smiles>

(2)<smiles>[13CH]N[13CH3]</smiles>

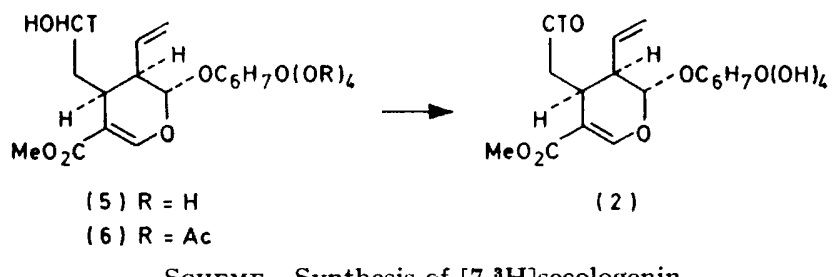

Scheme Synthesis of $\left[7^{-3} \mathrm{H}\right]$ secologenin

biosynthesis of monoterpenoid alkaloids. This labelled secologanin (2) was prepared in satisfactory radiochemical yield by use of sodium borotritiide in the reduction of $(2)$ to the $\left[7^{3} \mathrm{H}\right]$ alcohol, named secologanol (5), which was in turn reoxidized to $\left[7-{ }^{3} \mathrm{H}\right]$ secologanin (2) by treatment with Jones reagent. Previously it has been reported ${ }^{17}$ that reduction of secologanin (2) with $\mathrm{NaBH}_{4}$ leads to sweroside. If, however, in this reaction a large excess of borohydride is avoided and the $\mathrm{pH}$ is carefully controlled at 7.0 or the reaction is carried out in methanol at $0^{\circ}$, the reaction leads to secologanol (5) as outlined in the Scheme. Condensation of $\left[7-{ }^{3} \mathrm{H}\right]-(2)$ with tryptamine under standard conditions ${ }^{3}$ led to the desired tetrahydro- $\beta$-carbolines (3) and (4) labelled at the $\mathrm{C}-3$ position with tritium or the $[6-14 \mathrm{C}]$-epimers if $\left[2-{ }^{14} \mathrm{C}\right]$ tryptamine $(1)$ was used instead. The epimers were separated by chromatography. The synthesis of doubly labelled (3) was achieved by enzymatic con- densation of $\left[2-{ }^{14} \mathrm{C}\right]-(1)$ and $\left[7^{3} \mathrm{H}\right]-(2)$ using partly purified strictosidine synthase. In this case the ${ }^{3} \mathrm{H}$ and ${ }^{14} \mathrm{C}$ labels were within the same molecule. The position of the tritium label in compound (3) has been proven previously ${ }^{1}$ to be in the desired 3-position. The stereochemical assignment of the products (3) and (4) to the $\alpha$ - or $\beta$-series was achieved by several methods. ${ }^{10}$ The c.d. spectra of the acetylated products and the n.m.r. spectra of the lactams derived from these products 10,18 showed clearly their stereochemical relationship; e.g. only the $\alpha$-epimer gives the anomalous acetate signal at $\delta 1.23 .^{6,19,10}$ Furthermore it was found ${ }^{10}$ that t.l.c. of the $\beta$-epimer with a solvent system containing diethylamine converts it quantitatively into the lactam, while the $\alpha$-epimer under these conditions is stable and easily separable from the $\beta$-lactam. This marked difference in the stability of the $\alpha$ - and $\beta$-epimers is in full agreement with previous observations. ${ }^{3}$

In a preliminary experiment $\left[7^{3} \mathrm{H}\right]$ secologanin $(2)$ and $\left[{ }^{2-14} \mathrm{C}\right]$ tryptamine (1) (as an internal check) were fed simultaneously to Rauwolfia canescens which contains both $3 \alpha-$ and $3 \beta$-alkaloids. Under the conditions chosen, no chemical condensation of both compounds occurred in the feeding solution. As can be seen in Table $1,\left[{ }^{14} \mathrm{C}\right]$ tryptamine (1) was incorporated into all four alkaloids (7) - (10) examined; interestingly enough, however, all the $3 \alpha$-alkaloids contained a relatively high ${ }^{3} \mathrm{H}:{ }^{14} \mathrm{C}$ ratio, while the $3 \beta$-alkaloid $(10)$ showed a very low isotope ratio suggesting that the tritium label was lost to a large extent. Thus, already at this stage there was an indication that the 3 $\beta$-reserpiline (10) is not formed from (4) since in this case the ${ }^{3} \mathrm{H}$ label should be retained to a similar extent as in the $3 \alpha$-series. The observed considerable variation in the ${ }^{3} \mathrm{H}:{ }^{14} \mathrm{C}$ ratio of the $3 \alpha$-alkaloids may reflect a differential uptake and internal dilution rate for both precursors.

The decisive test was carried out by using doubly labelled $\left[3^{3} \mathrm{H}, 6{ }^{14} \mathrm{C}\right]$ strictosidine $(3)$ which was fed to $R$. canescens shoots to afford the incorporation recorded in Table 2. The ${ }^{14} \mathrm{C}$ label of (3) was incorporated satisfactorily into all five alkaloids under investigation. However, only the $3 \alpha$-alkaloids showed the same ${ }^{3} \mathrm{H}:{ }^{14} \mathrm{C}$ ratio as the precursor, while both alkaloids (10) and (11) with the $\beta$-configuration lost the tritium label to a large extent. The same phenomenon was found if the double labelled strictosidine (3) is supplied to Mitragyna speciosa which contains, among other alkaloids, mitragynine (13) and speciociliatine (14) which differ only in the stereochemistry of $3-\mathrm{H}$. In this plant also, as for

TABLE 1

Simultaneous application of $\left[7^{3} \mathrm{H}\right]$ secologanin and $\left[2-{ }^{14} \mathrm{C}\right]$ tryptamine to young shoots of $R$. canescens

Total activity fed ${ }^{3} \mathrm{H}$-Secologanin $44.10 \times 10^{6}$ d.p.m. $\left(69.38 \times 10^{6}\right.$ d.p.m. $\left.\mu \mathrm{mol}^{-1}\right)$

Alkaloid isolated

$\alpha$-Yohimbine (7)

Isoreserpiline (8)

Aricine (9)

Reserpiline (10)

$\begin{array}{cc}{ }^{3} \mathrm{H} & { }^{14} \mathrm{C} \text { Incorporation } \\ \text { Stereochemistry. } & (\%) \\ \alpha & 0.14 \\ \alpha & 0.05 \\ \alpha & 0.02 \\ \beta & 0.04\end{array}$

${ }^{14} \mathrm{C}$ Specific activity

(d.p.m. $\mu \mathrm{mol}^{-1}$ )

$1.18 \times 10^{4}$

$3.47 \times 10^{3}$

$1.24 \times 10^{3}$

$2.91 \times 10^{3}$
${ }^{3} \mathrm{H}:{ }^{14} \mathrm{C}$
$8.15: 1$
$14.82: 1$
$10.49: 1$
$0.98: 1$ 
TABLE 2

[3- $\left.{ }^{3} \mathrm{H}, 6-{ }^{14} \mathrm{C}\right]$ Strictosidine feeding experiments in different A pocynaceae plants

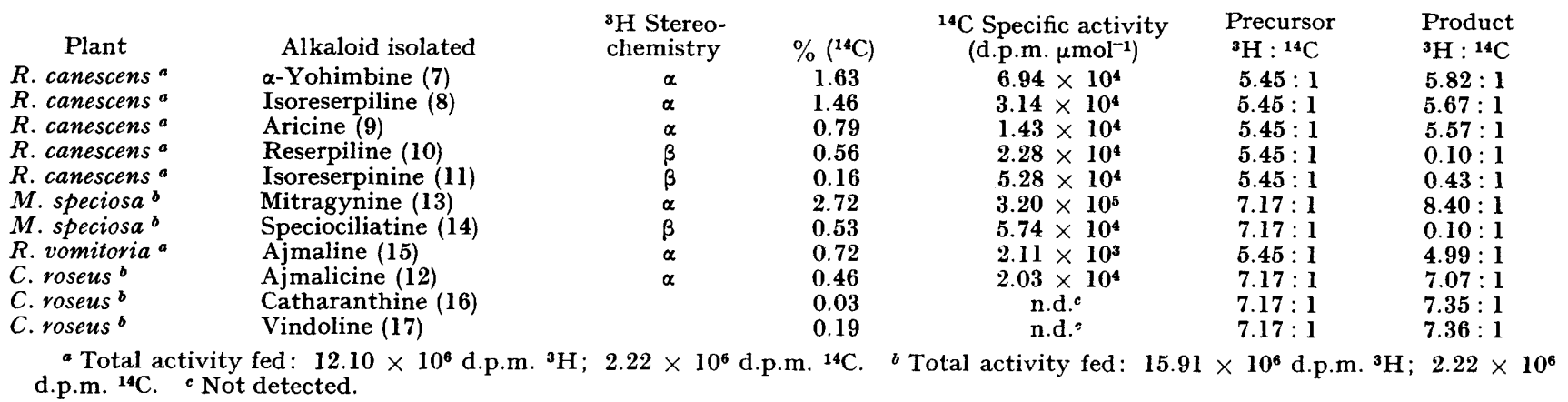

the Rawwolfia alkaloids, during the biosynthesis of the $\alpha$-epimer the ${ }^{3} \mathrm{H}$ label was retained while the $\beta$-alkaloid lost the ${ }^{3} \mathrm{H}$ atom (Table 2 ). This clearly demonstrates that $3 \alpha$-as well as $3 \beta$-alkaloids are derived from strictosidine (3) and that the biosynthetic conversion of (3) into the $3 \beta$-alkaloids proceeds with loss of hydrogen at
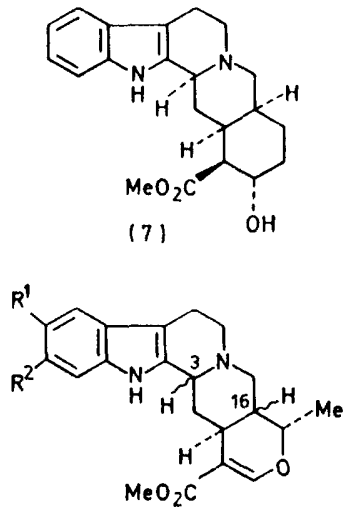

(8) $R^{1}=R^{2}=$ OMe, $3 \alpha, 16 \alpha$ (9) $R^{1}=O M e, R^{2}=H, 3 \alpha, 16 \alpha$ (10) $R^{1}=R^{2}=O M e, 3 \beta, 16 \alpha$

(11) $R^{1}=H, R^{2}=O M e, 3 \beta, 16 \alpha$

(12) $R^{1}=R^{2}=H, 3 \alpha, 16 \beta$

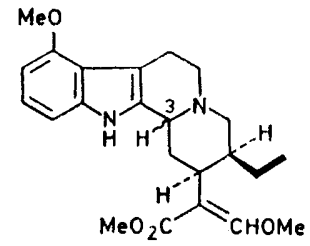

(13) $3 \alpha$

(14) $3 \beta$<smiles></smiles>

(20)

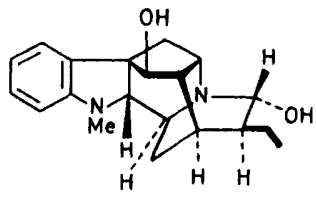

$\{15\}$
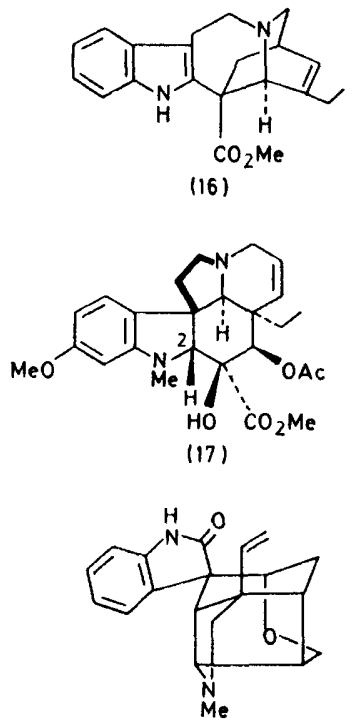

(18)

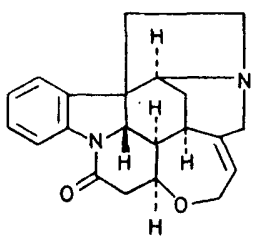

(19)
C-3, while it is retained in the formation of the $3 \alpha$-series. Further. to demonstrate that strictosidine $(3)$ is a general precursor this compound was fed to Rawwolfia vomitoria and $C$. roseus. The results of this double-labelling experiment showed that the main skeleton of $(3)$ is incorporated intact without appreciable change in the ${ }^{3} \mathrm{H}:{ }^{14} \mathrm{C}$ ratio (Table 2). The incorporation of the $\mathrm{C}-3$ tritium atom of $(3)$ in the $C$. roseus alkaloids (12), (16), and (17) is in agreement with the earlier observation that $\left[{ }^{3}-{ }^{3} \mathrm{H}\right] \operatorname{loganin}$ was incorporated [which labels the formyl hydrogen in secologanin and thus $3-\mathrm{H}$ of (3)] into these alkaloids and that no hydrogen migration was involved during the biosynthesis of these compounds. ${ }^{20}$ Furthermore $\left[6-{ }^{14} \mathrm{C}\right]$ strictosidine (3) was transformed into gelsemine (18) in Gelsemium sempervirens $(0.47 \%$ incorporation), into strychnine (19) $(0.12 \%$ incorporation) in Strychnos nux-vomica, and into vincadifformine (20) $(0.14 \%$ incorporation) in Vinca major. In addition, feeding of $\left[6^{14} \mathrm{C}\right]-(3)$ resulted in the formation of heavily labelled alkaloids of Rhazia stricta, Rhazia orientalis, Amsonia tabernaemontana, Vallesia glabra, Cinchona pubescens, and Uncaria gambir; the identification of the labelled compounds is in progress. In all these cases parallel feeding experiments were performed using $\left[3-{ }^{3} \mathrm{H}, 6-{ }^{14} \mathrm{C}\right]$ vincoside (4) of similar specific activity as that of (3) used in Table 2. However, in none of the investigated plants was any incorporation of vincoside (4) into the alkaloid fractions (detection limit $<0.001 \%$ incorporation) observed. Therefore it can be stated that within the four plant families thus far investigated Apocynaceae, Loganiaceae, Rubiaceae, and Nyssaceae, ${ }^{15}$ strictosidine (3) is the sole biosynthetic precursor for the elaboration of the monoterpenoid indole alkaloids derived from the condensation of tryptamine (1) with secologanin (2). Furthermore strictosidine (3) gives rise not only to Corynanthe ( $3 \alpha$ - and $3 \beta$-series), Iboga, and Aspidosperma type alkaloids but also to more complex structures such as those of strychnine, gelsemine, and probably quinine. Strictosidine (3) can therefore be regarded as the universal precursor for monoterpenoid indole alkaloids.

\section{EXPERIMENTAL}

General Directions.-Unless otherwise stated u.v. spectra (Beckmann model 24) and optical rotations (Perkin-Elmer 
model 141) were determined for solutions in methanol. I.r. spectra were taken for $\mathrm{KBr}$ discs and n.m.r. spectra for solutions in deuteriochloroform. T.l.c. was carried out on silica SIL G/UV ${ }_{254}$ (Machery-Nagel) Polygram plates, if not otherwise stated. Proportions given for mixed solvents are by volume.

Measurement of Radioactivity.-Liquid scintillation counting was used for the measurement of ${ }^{3} \mathrm{H}$ and ${ }^{14} \mathrm{C}$ activities (Berthold liquiszint BF 5000). Radioactive samples were dissolved in methanol and liquid scintillator added $(10 \mathrm{ml})$; quoted activities were corrected by the internal standard method for self absorption. The relative efficiencies were obtained by counting $\left[U_{-}{ }^{3} \mathrm{H}\right]-$ and $[$ methyl-14 $\mathrm{C}]$-toluene standards (Amersham). T.l.c. plates were scanned with a Berthold DC II instrument.

Plant Material.- The experimental plants were grown in a greenhouse, in most cases from seeds. The plants were later transferred to a Phytotron chamber at $28{ }^{\circ} \mathrm{C}$ at $75 \%$ relative humidity and 10000 lux light in a $16 \mathrm{~h}$ day, $8 \mathrm{~h}$ night photoperiod. Single apical cuttings $c a .5-10 \mathrm{~cm}$ in length of vigorously growing plants were used for the feeding experiments.

Feeding Techniques.-In the case of Strychnos and $R$. vomitoria growing seedlings with intact root systems were fed by the capillary feeding technique, ${ }^{21}$ In all other cases the labelled compounds $(1.16 \mu \mathrm{mol})$ were fed through the freshly cut ends of shoots. The labelled compounds were dissolved in water $(0.5 \mathrm{ml})$ containing up to $5 \%$ ethanol. When uptake was complete, water was added periodically. The plants were allowed to metabolize for $24 \mathrm{~h}$ under the climatic conditions stated above and were then analysed for alkaloids.

Isolation and Purification of Alkaloids.-The plant material (typically $0.5 \mathrm{~g}$ fresh weight) was cut into small pieces and exhaustively extracted with boiling $80 \%$ aqueous ethanol. The extract was taken to dryness, the residue taken up in methanol, and an aliquot portion subjected to t.l.c. Zones containing alkaloid were eluted and rechromatographed in the subsequent solvent system. The systems for the Rauwolfia alkaloids were: acetonelight petroleum (b.p. $40-60^{\circ}$ )-diethylamine $20: 70: 10$; xylene-diethylamine $8: 2$; and cyclohexane-chloroformdiethylamine $5: 4: 1$. For the Catharanthus alkaloids: ethyl acetate-ether-light petroleum (b.p. 40-60 $20: 20: 40$; chloroform-n-hexane-acetone $25: 38: 20$; and ethyl acetate-ether-n-hexane $20: 20: 8$; for Mitragyne alkaloids: ethyl acetate-propan-2-ol- $\mathrm{NH}_{3}-\mathrm{n}$-hexane $56: 1: 0.5: 36$; xylene-methyl ethyl ketone-diethylamine $75: 35: 2$; ether-diethylamine $95: 5$; chloroform-diethylamine $9: 1$.

Purification to constant specific activity was followed by u.v. spectroscopy. If necessary the alkaloids were diluted with carrier material and crystallized to constant specific activity following published procedures. ${ }^{22}$

Preparation and Synthesis of Compounds.-Secologanin was isolated from Lonicera tartarica by the procedure of Hutchinson as given in ref. 23.

Secologanol (5). Sodium borohydride $(80 \mathrm{mg})$ was added in small portions to a solution of secologanin $(500 \mathrm{mg})$ in methanol $(5 \mathrm{ml})$ at $0^{\circ}$ under stirring. After $10 \mathrm{~min}$ the mixture was slightly acidified with acetic acid. The solution was evaporated to near dryness and the residue chromatographed on preparative plates $\left(\mathrm{GF}_{254} ; 1 \mathrm{~mm}\right.$; solvent acetone-chloroform-water $80: 20: 5$ ). The band of $R_{\mathrm{F}} \mathbf{0 . 3 0}$ was eluted and rechromatographed (Polygram) in the same solvent system $\left(R_{\mathrm{F}} \mathbf{0 . 3 5}\right)$. Pure secologanol was obtained as a powder (300 mg) (Found: C, 50.4; H, 6.8. $\mathrm{C}_{17} \mathrm{H}_{26} \mathrm{O}_{10}, \mathrm{H}_{2} \mathrm{O}$ requires $\left.\mathrm{C}, 50.0 ; \mathrm{H}, 6.9 \%\right)$; $v_{\max }$ 3330,1685 , and $1627 \mathrm{~cm}^{-1}$; $[\alpha]_{\mathrm{p}}{ }^{25}-127^{\circ}(c 0.95)$; $\lambda_{\max }$. $237 \mathrm{~nm}(\log \varepsilon 4.01)$.

Penta-acetylsecologanol (6). A solution of secologanol $(35 \mathrm{mg})$ in pyridine $(1 \mathrm{ml})$ and acetic anhydride $(1 \mathrm{ml})$ was allowed to react overnight at room temperature. The solution was then added to ice-water and evaporated. The residue was chromatographed (t.l.c. solvent chloroformmethanol $98: 2)$. The main band was eluted and recrystallized from methanol $\left(37 \mathrm{mg}\right.$ ), m.p. $130-131^{\circ}$ (Found: C, 54.4: $\mathrm{H}, 6.0 . \quad \mathrm{C}_{27} \mathrm{H}_{36} \mathrm{O}_{15}$ requires $\mathrm{C}, 54.0 ; \mathrm{H}, 6.0 \%$ ); $v_{\max } 1733,1700$, and $1628 \mathrm{~cm}^{-1}$; $[\alpha]_{\mathrm{D}}{ }^{25}-91.7^{\circ}(c 0.67$ in chloroform); $\lambda_{\max .} 232 \mathrm{~nm}(\log \varepsilon 4.03) ; m / e 600\left(M^{+}\right.$ $0.03 \%), 540(1), 331(14), 192(32), 169(100)$, and $115(14)$, the molecular ion was determined using the internal standard method; $\delta 1.93(3 \mathrm{H}, \mathrm{s}), 1.99(3 \mathrm{H}, \mathrm{s}), 2.01(3 \mathrm{H}$, s), $2.04(3 \mathrm{H}, \mathrm{s}), 2.09(3 \mathrm{H}, \mathrm{s}), 3.70(3 \mathrm{H}, \mathrm{s})$, and $7.36(1 \mathrm{H}$, d, $J 0.8 \mathrm{~Hz}$.

Synthesis of Precursors.- $\left[7_{-}{ }^{3} \mathrm{H}\right]$ Secologanol (5).-A solution of secologanin $(39 \mathrm{mg})$ in methanol $(0.5 \mathrm{ml})$ was added to sodium borotritiide $(100 \mathrm{mCi} ; 0.34 \mathrm{mg})$ at $0^{\circ}$. After 10 min at $0^{\circ}\left[7-{ }^{3} \mathrm{H}\right]$ secologanol was worked-up and purified by t.l.c. as above, radiochemical yield $59.0 \mathrm{mCi}$.

$\left[{ }^{7}{ }^{3} \mathrm{H}\right]$ Secologanin $(2) . \quad\left[7-{ }^{3} \mathrm{H}\right]$ Secologanol $(7.8 \mathrm{mg} ; 2$ $\mathrm{mCi})$ was dissolved in a mixture of methanol $(0.2 \mathrm{ml})$ and acetone $(0.7 \mathrm{ml})$ at $0^{\circ}$. To this mixture Jones reagent ${ }^{24}$ $(0.4 \mathrm{ml})$ diluted $1: 6$ with cold acetone was added slowly with stirring at $0^{\circ}$. After $30 \mathrm{~min}$ and again after $60 \mathrm{~min}$, diluted Jones reagent $(0.2 \mathrm{ml}$ each time $)$ was added. After a further $30 \mathrm{~min}$ the solvent was removed under nitrogen and the mixture subjected to t.l.c. (solvent acetonechloroform-water $80: 20: 5$ ). The band containing secologanin $\left(R_{\mathrm{F}} \mathbf{0 . 3 5}\right)$ was eluted and subsequently rechromatographed (solvent chloroform-n-propanol-methanol-water 45: 15:60:40; chloroform phase, $R_{\mathrm{F}} 0.66$ ). The yield was $0.41 \mathrm{mCi}(41 \%)$. Unchanged $\left[7^{-3} \mathrm{H}\right]$ secologanol was recovered $(1 \mathrm{mCi})$ after the first t.l.c. The position of the label in secologanin was determined by the formation of secologanin tetra-acetate and further oxidation to secoxyloganin tetra-acetate ${ }^{25}$ upon which all $\left[{ }^{3} \mathrm{H}\right]$ label was lost.

$\left[6-{ }^{14} \mathrm{C}\right]$ Strictosidine (3) and $\left[6-{ }^{14} \mathrm{C}\right]$ vincoside (4). To a solution of $\left[2-{ }^{14} \mathrm{C}\right]$ tryptamine bisuccinate $(50 \mu \mathrm{Ci} ; 1.44 \mathrm{mg})$ in $1 \mathrm{M}$-citrate buffer ( $\mathrm{pH} 4.0 ; 0.1 \mathrm{ml}$ ) secologanin $(48 \mathrm{mg}$ ) was added. The mixture was allowed to stand for $48 \mathrm{~h}$ at room temperature in the dark. $\left[6^{-14} \mathrm{C}\right]-(3)$ and $-(4)$ were isolated by t.l.c. Plates were developed twice using etherethanol $4: 1$ as solvent, which separated both epimers [(3) $R_{\mathrm{F}} 0.34$; (4) $\left.R_{\mathrm{F}} 0.26\right]$. The yield of each epimer was $15 \%$.

The same procedure was followed for the preparation of a mixture of $\left[3{ }^{3} \mathrm{H}\right]$ strictosidine $(3)$ and $\left[3-{ }^{3} \mathrm{H}\right]$ vincoside $(4)$; however, the mole ratio of tryptamine to $\left[7^{3} \mathrm{H}\right]$ secologanin was changed to $12: 10$.

$\left[3-{ }^{3} \mathrm{H}, 6^{-14} \mathrm{C}\right]$ Strictosidine (3). In a typical experiment $\left[{ }^{2-14} \mathrm{C}\right]$ tryptamine $(50 \mu \mathrm{Ci} ; 7 \mu \mathrm{mol})$ and $\left[{ }^{3-} \mathrm{H}\right]$ secologanin $(273 \mu \mathrm{Ci}, 7 \mu \mathrm{mol})$ were dissolved in a total volume of $5 \mathrm{ml}$ of 0.5M-potassium phosphate buffer ( $\mathrm{pH} 7.0$ ). Partially purified strictosidine synthase $\left(4.34 \mathrm{mg} ; 2670\right.$ pkat $\mathrm{mg}^{-1}$ ) was added and the mixture incubated at $30^{\circ}$ for $2 \mathrm{~h}$. The mixture was subsequently freeze-dried and the residue extracted with ethanol $(3 \times 0.5 \mathrm{ml})$. The organic phase was chromatographed (solvent acetone-methanol-diethyl- 
amine $70: 10: 10)$. The band containing strictosidine $\left(R_{\mathrm{F}} \mathbf{0 . 5 0 )}\right.$ was eluted with methanol and rechromatographed (solvent chloroform-methanol $4: 1$ ) , $R_{\mathrm{F}} \mathbf{0 . 2 5}$. The yield of doubly labelled product was $80.5 \mu \mathrm{Ci}{ }^{3} \mathrm{H}$ and $14.77 \mu \mathrm{Ci}{ }^{14} \mathrm{C}$ (overall yield in several runs 30\%); specific activity 39.0 $\mu \mathrm{Ci} \mu \mathrm{mol}^{-1}{ }^{3} \mathrm{H}$ and $7.14 \mu \mathrm{Ci} \mu \mathrm{mol}^{-1}{ }^{14} \mathrm{C}$. The specific activity was lowered if necessary by addition of unlabelled strictosidine.

Degradation of Doubly Labelled Ajmalicine. ${ }^{26}$ - Ajmalicine (12) $\left(27526\right.$ d.p.m. $\mu \mathrm{mol}^{-1}{ }^{3} \mathrm{H} ; 3894$ d.p.m. $\mu \mathrm{mol}^{-1}{ }^{14} \mathrm{C}$; $\left.{ }^{3} \mathrm{H}:{ }^{14} \mathrm{C} 7.07: 1\right)$ which was obtained from the feeding experiments of $C$. roseus using $\left[3-{ }^{3} \mathrm{H}, 6-{ }^{14} \mathrm{C}\right]-(3)$ as precursor (Table 2) was dissolved in a mixture of mercury(II) acetate $(4 \mathrm{mg})$ in acetic acid $(0.2 \mathrm{ml})$. The mixture was heated for $2 \mathrm{~h}$ at $60^{\circ}$. The solution was taken to near dryness and subjected to t.l.c. (xylene-methyl ethyl ketone-diethylamine, $70: 35: 2)$. Dehydroajmalicine $\left(R_{\mathrm{F}} 0.76\right)$ was clearly separated from ajmalicine $\left(R_{F} \mathbf{0 . 6 8}\right)$. Dehydroajmalicine was eluted with acidified methanol and the solvent evaporated to dryness. The residue was dissolved in methanol $(0.5 \mathrm{ml})$, sodium borohydride was then added $(5 \mathrm{mg})$, and after $10 \mathrm{~min}$ the product was purified by t.l.c. as above. The recovered ajmalicine (1 345 d.p.m. $\mu \mathrm{mol}^{-1}{ }^{3} \mathrm{H} ; 3282$ d.p.m. $\mu \mathrm{mol}^{-1}{ }^{14} \mathrm{C}$ ) showed a ${ }^{3} \mathrm{H}:{ }^{14} \mathrm{C}$ ratio of $0.41: 1$.

We thank Professor H. Inouye, Kyoto, for calling our attention to the possibility of using Jones oxidation for secologanol, Professor D. Arigoni, Zürich, for letting us have a copy of the Ph.D. thesis in ref. 22, Dr. J. D. Phillipson, London, for the kind gift of samples of (13) and (14), Professor H. S. Fong, Chicago, for samples of (8), (9), and (11), and Professor B. Zsadon, Budapest, for $( \pm)-(20)$. This research was supported by the Minister für Forschung und Technologie, Bonn.

[8/1923 Received, 6th November, 1978]

\section{REFERENCES}

1 Preliminary communication, M. Rueffer, N. Nagakura, and M. H. Zenk, Tetrahedron Letters, 1978, 1593.

2 A. R. Battersby, in 'The Alkaloids,' ed. J. E. Saxton, Spealist Pel iodical Reports, The Chemical Society, London, 1971, vol. 1, p. 31

3 A. R. Battersby, A. R. Burnett, and P. G. Parsons, J. Chem. Soc. $(C), 1969,1193$.

4 G. N. Smith, Chem. Comm., 1968, 912.

5 For a review see G. A. Cordell, Lloydia, 1974, 37, 219.

6 K. T. D. De Silva, G. N. Smith, and K. E. Warren, Chem. Comm., 1971, 905.

7 W. P. Blackstock, R. T. Brown, and G. K. Lee, Chem. Comm., 1971, 910.

8 K. C. Mattes, C. R. Hutchinson, J. P. Springer, and J. Clardy, $J$. Amer. Chem. Soc., 1975, 97, 6270.

J J. Stöckigt and M. H. Zenk, FEBS Letters, 1977, 79, 233.

10 J. Stöckigt and M. H. Zenk, J.C.S. Chem. Comm., 1977, 646.

11 G. N. Smith, personal communication.

12 R. T. Brown, J. Leonard, and S. K. Sleigh, Phytochemistry, $1978,17,899$

13 A. I. Scott, S. L. Lee, P. de Capite, M. G. Culver, and C. R. Hutchinson, Heterocycles, 1977, 7, 979.

${ }_{14}$ C. R. Hutchinson, A. H. Heckendorf, P. E. Dadonna, E. Hagaman, and E. Wenkert, J. Amer. Chem. Soc., 1974, 96, 5609.

$15 \mathrm{~A}$. H. Heckendorf and C. R. Hutchinson, Tetrahedron Letters, 1977, 4153.

16 R. T. Brown, J. Leonard, and S. K. Sleigh, J.C.S. Chem. Comm., 1977, 636.

17 A. R. Battersby, A. R. Burnett, and P. G. Parsons, J. Chem. Soc. $(C), 1969,1187$.

$18 \mathrm{~J}$. Stöckigt, Phytochemistry, 1979, in the press

19 R. T. Brown, C. L. Chapple, and A. G. Lashford, Phytochemistry, 1977, 16, 1619 .

20 A. R. Battersby and K. H. Gibson, Chem. Comm., 1971, 902.

$21 \mathrm{~J}$. Staunton, personal communication.

22 E.g. S. Escher, Ph.D. Thesis, University of Zürich, 1972.

23 G. Kinast and L.-F. Tietze, Chem. Ber., 1976, 109, 3640.

24 P. Bladon, J. M. Fabian, H. B. Henbest, H. P. Koch, and G. W. Wood, J. Chem. Soc., 1951, 2402

25 R. T. Brown, C. L. Chapple, D. M. Duckworth, and R. Platt, J.C.S. Perkin I, 1976, 160.

${ }_{26}$ E. Wenkert and D. K. Roychaudhuri, J. Org. Chem., 1956, 